Revista Mídia e Cotidiano

Artigo Seção Temática

Volume 11, Número 3, dezembro de 2017

Submetido em: 11/08/2017

Aprovado em: 04/12/2017

\title{
JUVENTUDE, TECNOLOGIA E INOVAÇÃO: uma construção mítica na contemporaneidade
}

\section{YOUTH, TECHNOLOGY, AND INNOVATION: a mythical construction in contemporaneity}

\author{
Bruno POMPEU ${ }^{1}$; Silvio Koiti SATO ${ }^{2}$
}

\section{Resumo:}

Este artigo reflete sobre uma característica central do contexto contemporâneo: a hipervalorização da juventude como um estilo de vida e como um mito desejado e consumido por toda a sociedade. A partir desta constatação, destacamos suas imbricações com o cenário tecnológico digital e os efeitos de sentido relacionados à busca constante pelo novo e pelo que aponta para o futuro. Para isso, partimos de um entendimento histórico e conceitual sobre a evolução dos temas juventude e tecnologia, até chegar ao protagonismo destes assuntos na atualidade. Finalmente, destacamos campanhas publicitárias que exemplificam o diálogo entre juventude e tecnologia, e sua apropriação pelas áreas de consumo, mídia e comunicação mercadológica.

Palavras-chave: Juventude; Tecnologia; Mito; Mídia; Publicidade.

\begin{abstract}
:
This article addresses a central question of the contemporary context: the overvaluation of youth as a lifestyle and as a myth desired and consumed by society. Based on this observation, the text explores its imbrications with the digital and technological scenario and the meaning effects related to the constant search for novelties and for what points to the future. In methodological terms, we start from a historical and conceptual understanding on the evolution of both subjects - youth and technology -, focusing the centrality of these themes in the present days. Finally, we highlight advertising campaigns that exemplify the dialogue between youth and technology, and we analyze their appropriation by the areas of consumption, media, and marketing communication.
\end{abstract}

Keywords: Youth; Technology; Myth; Media; Advertising.

\footnotetext{
${ }^{1}$ Publicitário, formado pela Escola de Comunicação e Artes da Universidade de São Paulo (ECA-USP). Mestre e Doutor em Ciências da Comunicação pela Universidade de São Paulo (PPGCOM-USP). Professor do Istituto Europeo di Design (IED-SP). E-mail: brupompeu@gmail.com.

${ }^{2}$ Doutor em Ciências da Comunicação pela ECA-USP. Docente na ESPM-SP, ECA-USP e FAAP. Pesquisador do GESC3 - Grupo de Estudos Semióticos em Comunicação, Cultura e Consumo. Sóciofundador da Casa Semio (SP). E-mail: silvio.sato@espm.br.
} 
Introdução

A existência num cenário globalizado, acelerado e mutante permeia a discussão teórica sobre a pós-modernidade. Mesclas, borramentos de limites e transformações em alta velocidade caracterizam novas práticas sociais, que têm no desenvolvimento tecnológico um eixo central, ao viabilizar dinâmicas informacionais e comunicacionais pós-massivas (LEMOS \& LEVY, 2010).

Podemos afirmar que o excesso, a complexidade e a fragmentação configuram um ambiente de incerteza para as definições de cultura e de identidade na contemporaneidade (HALL, 2000; GIDDENS, 2002), que são menos estritas em comparação a padrões anteriormente vigentes. Temos, enfim, a constatação de que vivenciamos compressões e ampliações em dimensões centrais como o espaço e o tempo (HARVEY, 1992).

Sobre esta última dimensão, podemos destacar dois pontos: o foco em relação ao tempo cronológico futuro, com uma crescente expectativa sobre o porvir - o que pode delinear um estado de constante ansiedade ao tentar antecipar e prever as transformações vindouras. O segundo ponto que impacta a temporalidade é a velocidade com que estas alterações podem surgir, uma aceleração crescente que pode contribuir também para a sensação de instabilidade.

A hipervalorização do futuro corresponde, de certa maneira, a um efeito de minimização em relação ao momento presente e, sobretudo, ao passado. Este passa a ser associado cada vez mais ao obsoleto, ao ultrapassado, ao velho e à decrepitude.

Ao aproximar esta temática da temporalidade ao mundo dos bens, partimos da premissa de que o processo de significação material é influenciado pelo tempo. Antes valorizado e desejado, o poder de transformação exercido pela passagem do tempo (o efeito pátina) é minimizado nos dias de hoje. Isto ocorre porque hoje os objetos são descartados rapidamente, e não há tempo de perceber seus efeitos em função tanto da lógica da obsolescência quanto do desenvolvimento técnico acelerado:

A rápida evolução da tecnologia informática torna cada vez mais comum a experiência de achar insuficiente e ultrapassado aquilo que, há muito pouco tempo, era objeto de desejo e sonho de consumo. (CARDOSO, 2012, p.154) 


\section{míDiA

Para além do raciocínio funcional, temos a presença da lógica efêmera da moda (LIPOVETSKY, 1989), ligada inicialmente apenas ao vestuário, com suas constantes renovações a cada estação, que passa a se estender para quase todos os outros setores da vida material, com destaque para o apelo da inovação tecnológica.

Há grande interesse nesta valorização do novo por parte do universo do consumo e da comunicação mercadológica: as empresas e as marcas precisam se mostrar atualizadas na sua oferta e na comunicação com o mercado. O objetivo é dialogar com esse consumidor que busca elementos que o auxiliem neste processo de preparação e adequação a um futuro em constante transformação, percebido muitas vezes como um risco inevitável para uma existência social e profissional bem-sucedida. Há um esforço contínuo para mostrar-se "em dia" e antenado, compondo uma estética sensível da inovação, num ambiente que valoriza o que é novo e jovem, e rejeita tudo que remeta ao que é velho e à pátina do passar do tempo.

É neste entroncamento entre tecnologia, consumo e comunicação mercadológica que destacamos a ascensão da juventude como estilo de vida característico e valorizado na pós-modernidade. Exploramos neste artigo a problemática relacionada à juventude como um valor positivo e aderente às ideias de renovação, ruptura e movimento (ENNE, 2011). Tendo isso em mente, para detalharmos a associação entre tecnologia e o público jovem, vamos primeiro (1) explorar conceitualmente a questão da tecnologia e seus impactos na esfera social; depois, (2) refletir sobre a construção do mito de juventude e sua complexificação ao longo do tempo. Por fim, (3) analisar o jovem e a tecnologia no discurso marcário.

\section{Tecnologia e inovação}

Podemos traçar paralelos entre a hipervalorização da juventude e a ascensão da tecnologia como característica central da sociedade contemporânea, comprovada pela denominação de Sociedade em Rede (CASTELLS, 1999).

O desenvolvimento das Novas Tecnologias de Informação e Comunicação (NTICs) foi acelerado nas últimas décadas: a popularização das tecnologias digitais, presentes no cotidiano de grande parte dos indivíduos, trouxe o desenvolvimento de 
práticas que configuraram uma cultura digital, chamada também de cibercultura (LEMOS \& LEVY, 2010). Com um simples celular conectado às redes sem fio, ocorrem múltiplas dinâmicas comunicacionais que exemplificam características centrais da cibercultura, como o empoderamento do indivíduo a partir de possibilidade de armazenamento, edição e emissão de conteúdos. A partir daí ocorre a interação numa topologia em rede, que é planetária e que possibilita a propagação de conteúdos os mais diversos no ciberespaço. Com isso, há a reconfiguração de práticas associadas à comunicação de massa e à indústria cultural, com novas funções pós-massivas que englobam aspectos econômicos, políticos e educacionais, dentre outros.

Esta cultura da rede possui características que valorizam a transitoriedade e o efêmero, já que se trata de um ambiente em constante transformação, com novas possibilidades informacionais a partir do desenvolvimento de inovações tecnológicas, materializadas por aplicativos, dispositivos e redes cada vez mais onipresentes. Com isso, desenvolve-se uma comunicação ubíqua, com caráter interativo, remixado e móvel, que pode ser simbolizada pelas plataformas de redes sociais da Internet. Nelas, mecanismos de interação e disputa por capital social são amplificados, além do desenvolvimento de uma construção identitária que ocorre com a criação de múltiplos perfis virtuais que são manipulados e midiatizados constantemente pelos indivíduos em práticas públicas e coletivas. E, como se sabe, todas essas maravilhosas possibilidades dependem de aparelhos, plataformas, gadgets - bens tecnológicos - que, por sua vez, só funcionam se devidamente renovados e atualizados.

Temos uma lógica de aceleração e descarte que se apoia muitas vezes na tecnologia como argumentação racional: novas tecnologias em hardware e software apresentam funcionalidades e benefícios que não existiam anteriormente, como se o mundo, tecnológico, fosse apenas científico, exato, repleto de dados coletados por sensores e organizados por algoritmos em nuvens de informação que compõem a base para a chamada inteligência artificial. Esse mesmo mundo proporcionaria experiências com a tecnologia que são uma combinação sedutora e fetichista de sensações imersivas, que mesclam realidades virtuais, híbridas e aumentadas, e que são vivenciadas de forma individual e coletiva, sempre com um encantamento inicial. Isto pode ser explicado 
porque estas experiências parecem apontar para novas direções, quebrar barreiras de espaço e tempo e, com isso, trazer a sensação de maior poder para o indivíduo.

Por outro lado, na lógica da racionalidade técnica e do cientificismo, a tecnologia parece trazer a inevitabilidade e o determinismo, algo de que não se pode escapar ou fugir (o futuro coletivo) a fim de manter-se a eficácia do sistema produtivo (NOVAES \& DAGNINO, 2004). Ampliando-se este conceito, é preciso também garantir a eficácia dos indivíduos ativos, participantes da sociedade. Só se pode permanecer ativo, atraente e integrado se assim forem também as tecnologias que você compra, usa, ostenta e descarta.

Com isso, percebemos que a suposta inevitabilidade da tecnologia ameniza uma construção histórica, cultural e social que reflete interesses e disputas de cada sociedade. Sem adentramos em discussões polarizantes entre tecnófilos e tecnófobos, há de se reconhecer que, além do potencial democrático que as novas mídias representam, é preciso compreender os objetivos relacionados aos mecanismos de transmissão de significado associados à tecnologia. Ou seja, no processo de produção e consumo destes bens, há um sentido da inclusão que vai além da literacia digital, mas que envolve a inserção simbólica no futuro para quem os consome ou, pelo menos, a possibilidade de vivenciá-lo.

Este fenômeno ocorre em linha com o entendimento do jovem como early adopter de novidades tecnológicas, ou seja, como o target inicial para lançamentos de produtos e serviços. Isto porque identificam-se uma grande abertura dos jovens às novas tecnologias digitais e também a sua habilidade de se apropriar e usá-las de acordo com seus interesses. Além disso, a sua capacidade de usar novas tecnologias se torna um fator de superioridade em comparação às gerações anteriores, em um gap geracional maior do que o que normalmente se tem quando se pensa em tecnologia de forma mais ampla ao longo da história (CASTELLS et al, 2007).

Além disso, imagina-se que este público, situado no topo ou na ponta inicial das curvas de difusão da inovação (VEJLGAARD, 2017), possa disseminar novos hábitos e comportamentos para outras faixas etárias, influenciando e acelerando sua adoção por um público mais amplo, bem como o processo de introdução e massificação dos bens. 


\section{Juventude: do fato ao mito}

A ideia de juventude remonta ao final do século XIX e ao início do século XX, período de grandes transformações contextuais: guerras mundiais, inovações tecnológicas e comunicacionais, crescimento urbano e novos métodos de produção. Diversos autores (BARBOSA, 2012; ROCHA \& PEREIRA, 2009; CALDAS, 2008; TRAVANCAS, 2007) costumam atribuir justamente a esse contexto o surgimento factual de um grupo social delimitado pela questão etária - um contingente humano numericamente significativo, que já não encontrava espaço na figura da criança, dotado de corpo e atitude em estado de ebulição, que tampouco podia se enquadrar no perfil de um adulto, ainda com traços de ousadia e ânsia por liberdade.

E o que precisa ser destacado, neste ponto inicial, é o caráter de novidade que o conceito de juventude carrega. Enquanto homens e mulheres, adultos e crianças, moradores do campo e moradores da cidade, ricos e pobres, patrões e empregados, por exemplo, se constituem como grupos sociais já estabelecidos, estudados e devidamente conceituados há muito tempo - ainda que com profundas e imensas diferenças entre as perspectivas adotadas ao longo do tempo -, os jovens são um grupamento de pessoas relativamente novo:

O Jovem é jovem, pois a consciência da juventude, tal como a possuímos hoje, é bastante recente e só passou a ser percebida como uma categoria especial, como uma espécie de fase específica e importante da vida, a partir do século XIX, e sua efetiva expansão aconteceu na Primeira Guerra Mundial. (ROCHA \& PEREIRA, 2009, p. 15)

Mais ainda: uma categoria que nasce não do antagonismo com um ou com outro grupo, mas, sim, do interstício entre dois deles, uma vez que

a ideia de jovem e de juventude foi criada como um espaço liminar, uma espécie de lugar intermediário, que faz a transição entre uma maturidade adiada e uma infância espremida - algo como um limbo, uma passagem intermediária e, como tal, mediadora de diferenças entre estados diversos. (ROCHA \& PEREIRA, 2009, p. 15)

E, enquanto essa nova parcela da população crescia em termos numéricos e alcançava relevância nas dinâmicas sociais, o contexto socioeconômico e cultural 
favorecia a sua expansão simbólica - muito atrelada ao consumo, aliás. Foi ao longo de praticamente todo o século XX que a figura do jovem foi sendo cada vez mais contemplada pelas empresas, pelas marcas e pelos produtos. Com uma atitude própria um jeito específico de se comportar, de agir e de falar (aspecto ético) - e uma aparência também própria - um gosto que se manifestava em moda, alimentação, consumo cultural e tantas mais quanto fossem as ofertas (aspecto estético) -, os jovens passaram a ser a grande referência do mercado. Não é que os demais "targets" tenham deixado de ser importantes. Mas o fato é que, junto dos adultos, das mulheres, das crianças, dos trabalhadores ou dos empresários, os jovens passaram a aparecer como alvo do discurso publicitário. Os cortes de cabelo, o jeito de usar a roupa, a música e a maneira de dançar, os filmes, os points, tudo o que o jovem praticava ou consumia foi transformado em produto, em oferta, em possibilidade via consumo.

Daí que, por muitas décadas, tudo o que fosse novidade tenha sido primeiro associado ao público jovem. Se antes, de alguma maneira, os lançamentos e o início dos ciclos de produtos estavam sempre relacionados ao topo da pirâmide - social e/ou econômica -, aos poucos o jovem foi passando a ocupar esse espaço, incorporando simbolicamente os sentidos da novidade e da inovação.

É sintomático, por exemplo, que em 1936, para celebrar seu aniversário de 50 anos, a marca Coca-Cola tenha lançado um anúncio em que duas garotas igualmente jovens, vestidas de formas diferentes - cada qual adequada à sua época -, segurem ambas um copo do refrigerante. Ou seja: para falar de tradição, perenidade e permanência (50 anos), valores mais ligados ao universo da maturidade, a marca se vale de valores desde então relacionados à juventude: renovação, frescor, atualização etc.

A incorporação desses valores de juventude em uma figura reconhecível como jovem - como sempre se pode ver na publicidade, nos filmes e nos programas de televisão - acabou contribuindo para a construção de um jovem mítico, já menos necessariamente vinculado à realidade social. Com a plena supremacia simbólica do jovem sobre o adulto, a juventude passou a ser um valor desejado por todos. Ser jovem deixou de ser simplesmente ter pouca idade. E, se esse valor passou a estar mais em um produto do que numa faixa etária, mais em uma marca do que em uma atitude, mais em uma roupa do 
que em uma forma de pensar, o acesso a essa juventude se tornou plenamente disponível a qualquer um que possa consumir.

Hoje, o que se percebe é o recrudescimento e a complexificação dessa questão. Não apenas a juventude continua sendo o grande polo semântico para onde se dirigem os vetores estéticos, comportamentais e simbólicos das sociedades urbanas ocidentais, como também o cenário tecnológico-midiático contribui para uma percepção de que é possível se alcançar a eterna juventude. Mais do que isso: hoje, a julgar pelo que vê e se transmite pelas telas digitais da televisão, dos computadores, dos tablets e dos celulares, já é possível envelhecer e ficar mais novo, fazer aniversário e perder as rugas, avançar no tempo e continuar jovem.

Assim, tendo por base estudos de diferentes perspectivas teóricas - história, sociologia, antropologia e comunicação -, apresentamos a seguir uma proposta de organização para o conceito de juventude em três dimensões complementares e coexistentes:

1. Juventude etário-biológica: determinado período na vida do indivíduo, marcado pela puberdade e pela sobreposição entre infância e a maturidade.

2. Juventude psicológico-comportamental: conjunto de atitudes e gostos que manifestam em determinada época os valores típicos da juventude.

3. Juventude mítico-simbólica: persona criada e disseminada pela cultura, que encarna e representa os valores, servindo de modelo a todos.

Ou seja: por mais que (1) a juventude, como faixa etária, continue existindo, ela se expressa inevitavelmente em (2) uma série de aspectos concretos ligados ao consumo e tem obrigatoriamente como modelo (3) uma figura mítica, irreal, um construto semântico/simbólico plasmado na cultura vigente.

Só que, quando se fala em mito, está se falando em algo que transcende ao concreto, ao cotidiano e ao individual - que vai além do que acima se apresentou e se classificou. Segundo Joseph Campbell, “mitos são metáforas da potencialidade espiritual do ser humano" (1990, p. 5). Em outras palavras, mitos são histórias que as sociedades criam para dar sentido à vida, para fortalecer a sua integração e para enfrentar os desafios que o mundo e o tempo lhes impõem: 
O mito é o sonho público, e o sonho é o mito privado. Se o seu mito privado, seu sonho, coincide com o da sociedade, você está em bom acordo com seu grupo. Se não, a aventura o aguarda na densa floresta à sua frente. (CAMPBELL, 1990, p. 42)

Ou seja: a juventude, como valor, é uma construção cultural que não apenas serve para que todos saibamos o que é ser jovem (e o que fazer para sê-lo) em determinado tempo, mas que também assume um sentido de mito - sintetizando e expressando nossas buscas, nossas angústias e nossas agruras diante do imponderável da vida. Vale considerar que o mito é, segundo Anspach,

construto cultural vinculado ao consumo, à moda e às visões e anseios particulares e específicos de uma época ou de um grupo de indivíduos cuja fé nada mais é que produto descartável e substituível como qualquer outro (1998, p. 16).

De modo que se evidencia uma apropriação desse mito pelo discurso publicitário, em uma lógica de hipervalorização da juventude. Se, por um lado, isso preenche, atualiza e dinamiza o conceito de juventude - ao mesmo tempo em que contribui muito para o sucesso das marcas -, pode criar também a sensação de que vivemos em um mundo bastante diferente deste que se encontra na realidade concreta do dia-a-dia.

Todas as novidades de mercado, todos os lançamentos, encontram hoje no jovem não exata ou obrigatoriamente o seu público-alvo efetivo. Melhor do que isso: o jovem mítico, construído como se tivesse um imenso ímpeto pelo inaugural, encarna a figura ideal para o consumo dessas novidades. Daí que, em meados dos anos 90, quando a internet e as chamadas "novas tecnologias" chegaram ao grande mercado, o jovem tenha sido desde então relacionado com o universo desse tipo de inovação. As máquinas de escrever e os telefones com fio ficaram para as secretárias (dos escritórios de homens mais velhos), os burocratas (ligados a uma lógica processual e administrativa antiga), as bibliotecárias (apegadas às estantes e aos livros de papel) e os jornalistas (das velhas redações, cheias de pessoas mais velhas, de roupa social e ventilador de teto, interessadas nas novidades que estavam chegando). Aos jovens, tudo: videogames, microcomputadores, telefones celulares, novas formas de se comunicar, novos métodos de trabalho, tudo novo. 


\section{Juventude, tecnologia e inovação no discurso midiático}

Basicamente, três tipos de discurso midiático contribuíram muito para 0 fortalecimento dessa tríplice associação (juventude-inovação-tecnologia), fortalecendo talvez até inadvertidamente - a construção desse mito contemporâneo que é o jovem tecnológico inovador.

- Jornalismo: quantas não foram as reportagens especiais, as matérias de capa ou os cadernos de domingo que se dispuseram a descrever e analisar o "jovem de hoje", dando destaque especial à sua relação com a tecnologia? Com uma linguagem pautada na objetividade, na transparência e no realismo, esse tipo de discurso contribuiu com a construção desse mito, fazendo crer que ele era verdadeiro, real, cotidiano e próximo. Everardo Rocha e Cláudia Pereira, ao analisar o papel dos meios de comunicação na construção e, sobretudo, na propagação dos mitos, afirmam:

É fundamental compreender o papel da mídia na construção de noções que são rapidamente incorporadas ao discurso da sociedade. A imprensa desempenha um papel crucial como um agente envolvido na construção coletiva das representações da juventude. $(2009$, p. 32)

- Entretenimento: filmes, novelas, quadrinhos, livros... foram vários os conteúdos narrativos ficcionais que apresentaram, sempre em uma aura de fuga e idealização, esse mesmo jovem mítico-simbólico, quase sempre dotado de poderes e qualidades relacionados ao uso das tecnologias. Esse tipo de narrativa, conquanto fantasioso, sempre trouxe conforto - tanto ao jovem quanto ao adulto. Trata-se de uma das funções básicas do mito, conforme explica Joseph Campbell:

Jovens em geral simplesmente se deixam arrebatar pelo assunto. A mitologia lhes ensina sobre a sua própria vida. A mitologia tem muito a ver com os estágios da vida. Todos os mitos têm a ver com o novo papel que você passa a desempenhar, com o processo de atirar fora o que é velho para voltar com o novo, assumindo uma função responsável. (1990, p. 12)

- Publicidade: se esse jovem, como mito contemporâneo, está ligado diretamente ao consumo, é até previsível que o discurso das marcas tenha dele se valido à exaustão. Esse jovem, nas propagandas das marcas, carrega valores, gera aspiração e provoca desejo. Ou seja: oferece a chave de acesso a esse universo encantador que foi criado e 
fortalecido nos dois tipos de discurso acima citados. Enquanto o discurso jornalístico contribui com o aspecto verossímil e o discurso do entretenimento desenvolve os conteúdos fantasiosos sobre o assunto, a publicidade cumpre o dever de oferecer esses sentidos ao consumidor, sempre por meio do consumo. Chegado ao ponto de se poder afirmar que "a narrativa publicitária parece ser aquela que mais vem contribuindo para uma espécie de apologia ao que poderíamos chamar de um processo juvenilizante da sociedade" (ROCHA \& PEREIRA, 2009, p. 60).

Vamos nos aprofundar especificamente no discurso publicitário. Utilizaremos uma das campanhas publicitárias mais recentes da marca Itaú (julho de 2016), que tem claramente se sustentado sobre o valor da juventude e a sua relação com o universo da tecnologia e da inovação. A estrutura básica se repete: as protagonistas Neuza e Lilia duas mulheres na faixa dos oitenta anos - recebem personalidades da internet - youtubers, influenciadores digitais, como se queira chamar - e, juntos, conversam sobre algum assunto transversal às suas gerações. Com Felipe Castanhari, por exemplo, o tema são as brincadeiras de criança; com Pathy dos Reis, a questão é a comunicação entre as pessoas, e assim por diante.
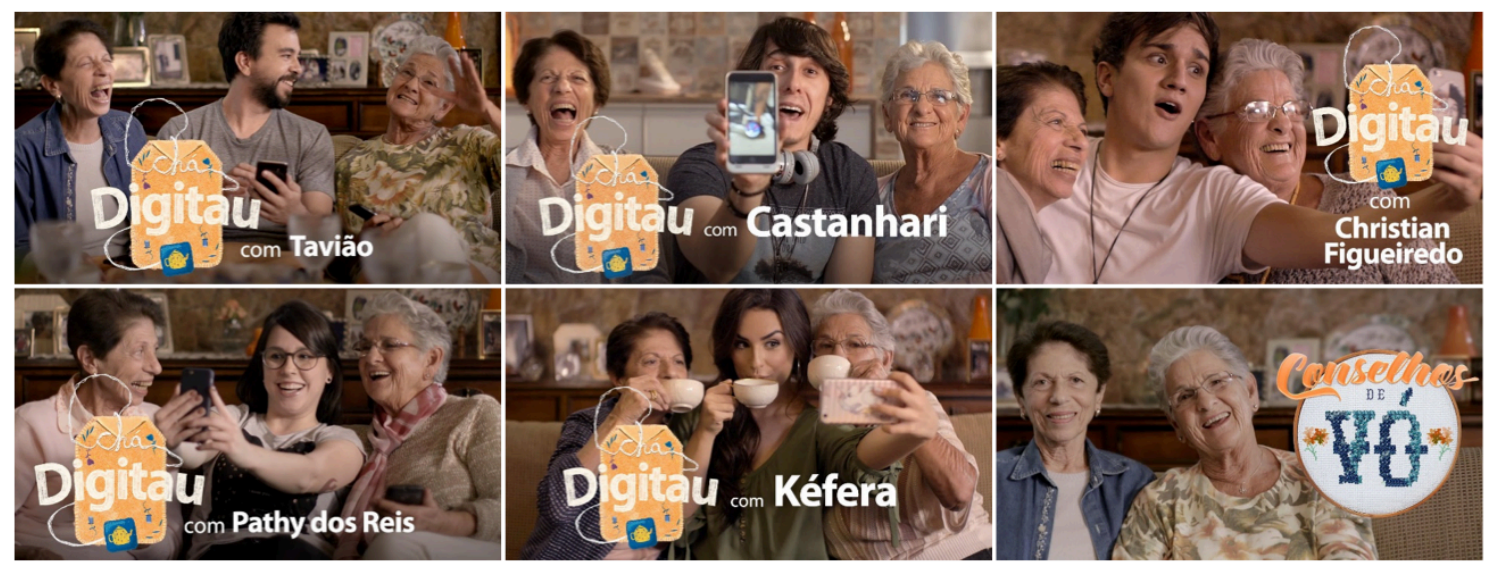

Figura 1 - Chá Digitau: Neuza e Lilia recebem personalidades do YouTube.

Fonte: www.youtube.com/itau

De repente, o celular passa a ser o centro da conversa, convertendo-se, ele sim, no elemento que, no contexto dos filmes, integra gerações tão distantes, com 
comportamentos tão diferentes. Se, antigamente, as brincadeiras eram feitas na rua, com objetos simples e baseadas na atividade física, a narrativa faz supor que hoje a brincadeira se dá apenas através da tela do celular - como se isso excluísse a saída à rua, o contato física e a agitação típica das crianças. Se antigamente a comunicação entre as pessoas era presencial, uni ou no máximo bidirecional, o anúncio sugere que hoje as pessoas só se comunicam por aplicativos de vídeo instantâneo - sem considerar que o telefone continua existindo e que, muitas vezes, é ele (e só ele - no máximo seus substitutos mais diretos) que pode atender a uma necessidade comunicacional.

Há filmes ainda com Kéfera, Tavião e Christian Figueiredo, todos eles com milhões de seguidores em seus perfis nas redes sociais. E a lógica por trás dos filmes é sempre a mesma: as "vovloggers" - como são chamadas as amigas octogenárias, numa combinação com as palavras vovós e vloggers - relatam aos convidados como se davam as coisas décadas atrás, para depois receberem uma explicação de como essas mesmas coisas acontecem hoje em dia, com a interferência das tecnologias digitais. Talvez seja como Joseph Campbell previu:

Surgirá uma nova geração, muito vigorosa, com um penteado diferente, e você pensará: "Bem, que ela tome o meu lugar". As mitologias têm de cuidar dessa situação de retirada. (2008, p. 42)

Mas o fato é que, ao menos no mundo criado pela propaganda do Itaú, em que os mais velhos já aparecem minimamente adaptados ao universo digital (abrindo conta, realizando DOCs e mandando mensagem para o gerente), a função do jovem hiperconectado é apresentar aos velhos um mundo maravilhoso que (só) eles dominam. Um mundo de brincadeiras, hábitos, gostos e palavras radicalmente novos e diferentes do que se tinha no passado.

Outra marca que tem se valido dessa figura mítica do jovem é a Vivo, com uma estratégia discursiva também bastante interessante. O filme "Viver é a melhor conexão" (abril de 2016), anunciou o novo posicionamento da marca - "viva tudo", destacando a amplitude, a ubiquidade e a integração dos serviços oferecidos pela marca. Para isso, enfileirou uma série de imagens de situações cotidianas e as relacionava cada uma com uma frase típica do universo digital. $\mathrm{O}$ menino sem um dos dentes da frente, por exemplo, 
recebia a frase "Abrindo nova janela"; a filha parecida com a mãe, "Copy\& paste"; o homem que larga tudo para abrir um café, "Reiniciando o sistema", e assim por diante.

A ideia, como não é difícil perceber (embora sofisticada em sua essência), é evidenciar como o mundo digital (das frases) e o mundo dito real (das imagens) são próximos. Dessa forma, valores como a humanização, a afetividade e a possibilidade de identificação, mais evidentes na esfera concreta do cotidiano, são transferidos para a marca. E quem assume essa posição intersticial é justamente o jovem.

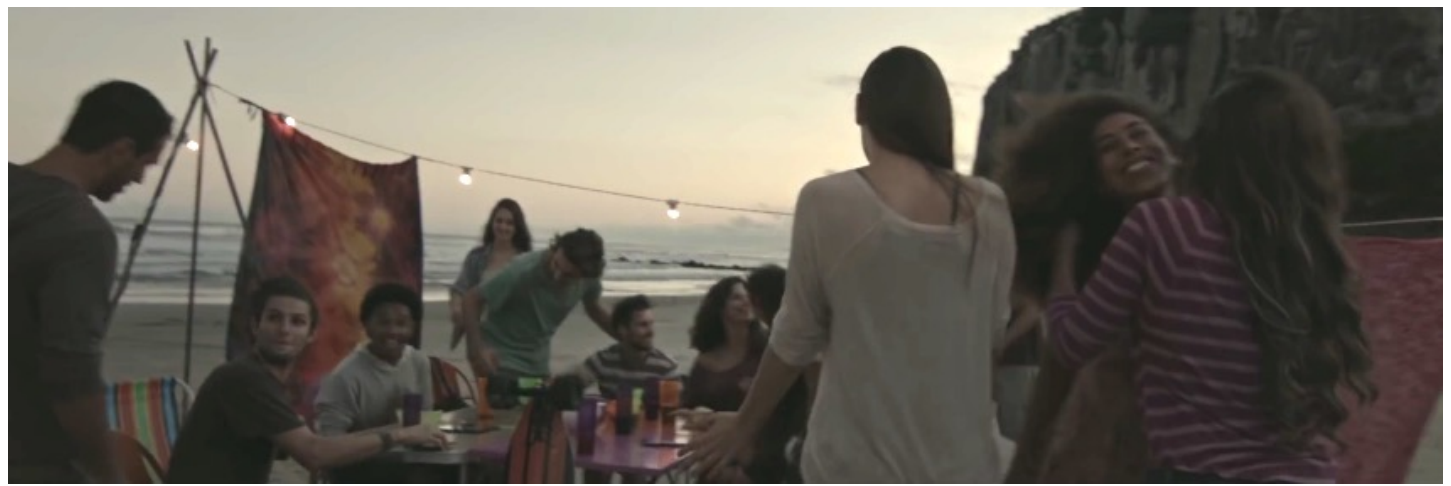

Figura 2 - "Viver é a melhor conexão": o jovem entre o digital e o real.

Fonte: www.youtube.com/vivo

Mais recente, embora ainda alinhado com a campanha citada acima, o filme "Neste Natal viva tudo" (dezembro de 2016), segue a mesma lógica, mas com destaque ainda maior à questão das tecnologias e à presença do jovem. No filme, vários jovens aparecem manuseando seus celulares, quase sempre explorando possibilidades tecnológicas bastante atuais (comunicação por vídeo em tempo real, troca de rostos na imagem da câmera, compartilhamento de memes e correntes etc.), em imagens que se contrapõem ao texto.

A ideia central desta vez é aproximar passado e futuro, propondo um questionamento verbal ("Dizem que hoje as crianças não escrevem cartas", "Dizem que não olhamos mais nos olhos uns dos outros"), que se responde simultaneamente com um conteúdo imagético (menino escrevendo um e-mail ao Papai Noel, casal distante entre si conversando pela câmera do celular, respectivamente). 


\section{míDiA

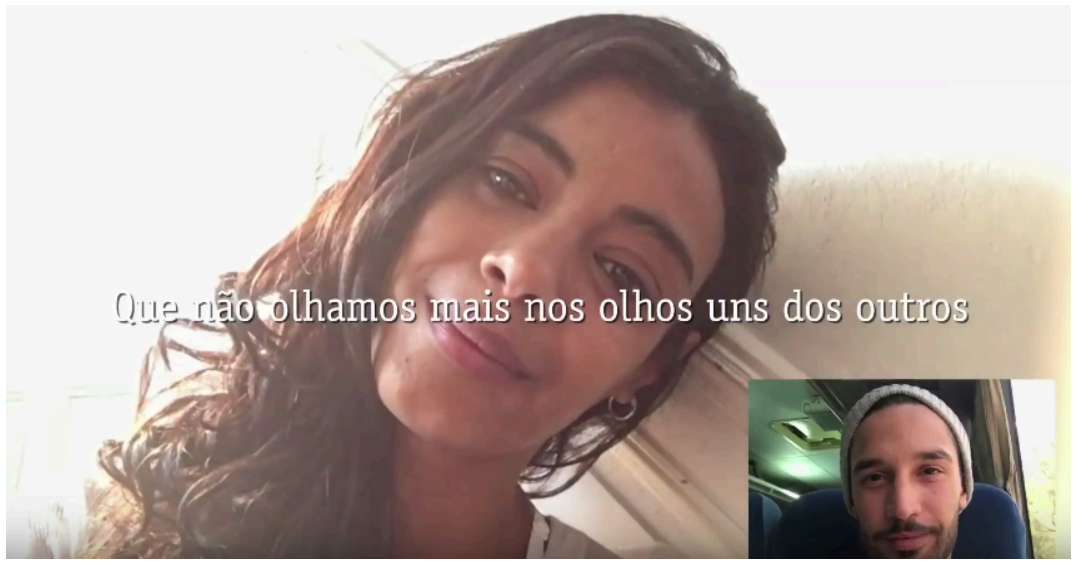

Figura 3 - "Neste Natal viva tudo": jovens conectados e ao mesmo tempo afetivos. Fonte: www.youtube.com/vivo

O que se destaca aqui, entretanto, é novamente a figura de um jovem retratado a partir da sua relação com as novas tecnologias. Se, nos filmes de Itaú, esse jovem tem a função de aproximar gerações, na campanha da Vivo, ele mostra que o online e o off-line são mais próximos do que se imagina. Nota-se, portanto, conforme visto acima, uma perspectiva determinista, positiva e otimista sobre a função e a presença da tecnologia no cotidiano das pessoas - dos jovens.

\section{Considerações finais}

Neste artigo, discutimos o mito da juventude e sua aproximação com os significados da tecnologia e a inovação no contexto do consumo e da produção publicitária.

Percebemos a hipervalorização da juventude e seu entendimento como um estilo de vida e um valor positivo na sociedade atual que dialoga com um tema central na existência humana: a relação com o tempo e o espaço e suas vertentes que vão desde o anseio pela imortalidade e a possibilidade de controle desta dimensão até à transposição e a sobreposição dos espaços.

Entretanto, a valorização da juventude que observamos vai além do tradicional horror à velhice e a tudo o que remete à morte e à finitude da existência humana. Parecemos buscar por significados relacionados a um universo juvenil que é corajoso e 
cheio de energia, por um lado, e ingênuo e espontâneo por outro, e que apontam uma tentativa de escapismo frente às incógnitas e incertezas do futuro.

Neste sentido, vale entender o tempo e o espaço como construções simbólicas, que refletem aspectos de uma determinada cultura e sua visão de mundo, ressignificadas mas nem sempre discutidas pela sociedade, e sempre que possível utilizadas no e pelo discurso das marcas em função do consumo. Em tempos de grande complexidade, insegurança e fragmentação, há desafios renovados em relação ao futuro, ao que nos espera. Visões mais ou menos sombrias surgem, mas têm como porto seguro a figura do novo, de algo que está ainda por vir e que poderá alterar possíveis cenários distópicos. $\mathrm{O}$ jovem, como símbolo do porvir, surge como um mito reconfortante (CAMPBELL, 2008, 1990) para várias gerações entorpecidas pela velocidade das transformações que estão sendo vivenciadas diariamente:

O simulacro pós-moderno se superimpõe ao real e implacavelmente o aniquila. A farsa é muito mais atraente que a verdade nua e crua. A farsa mítica é mais atraente que o real morno, rotineiro, decepcionante, verdadeiro, insosso. $\mathrm{O}$ consumo do falso ouro é muito mais sedutor do que o das verdades sem disfarce e sem tempero. (ANSPACH, 1998, pp. 192-193)

O "convite" à participação nesta lógica de valorização do binômio juventudetecnologia, e que tem como resultante a inserção no mundo da inovação e do futuro, pode ser percebido como uma imposição. É difícil evitar ou manter-se à parte desse mundo, tanto por razões emocionais e de pertencimento quanto por necessidades práticas. Podemos perceber esta lógica também como uma sinalização de que o sistema publicitário atual domestica o espírito da rebeldia e do frescor do jovem, inserindo-o como signo de adequação e ajustamento social. Neste sentido, talvez estejamos deixando de ter somente a hipervalorização (positiva, elogiosa, desejada e conformada) do jovem e passando a viver também a hiperexploração (ativa, intencional, estratégica e limitadora) dos significados associados ao mito do jovem na contemporaneidade.

\section{Referências}

ANSPACH, Silvia. Entre Babel e o Éden: criação, mito e cultura. São Paulo: Annablume, 1998. BARBOSA, Lívia (org.). Juventude e gerações no Brasil contemporâneo. Porto Alegre: Sulina, 2012. 
BAUMAN, Zygmunt. 44 cartas do mundo líquido moderno. Rio de Janeiro: Zahar, 2011. CALDAS, Waldenyr. A cultura da juventude: de 1950 a 1970. São Paulo: Musa, 2008. CAMPBELL, Joseph. As transformações do mito através do tempo. 2. ed. São Paulo: Cultrix, 2015.

Mito e transformação. São Paulo: Ágora, 2008.

O poder do mito. São Paulo: Palas Athena, 1990.

CARDOSO, Rafael. Design para um mundo complexo. São Paulo: Cosac Naify, 2012.

CASTELLS, Manuel. A Sociedade em Rede. São Paulo: Paz e Terra, 1999. et al. Mobile communication and society: A global perspective. MIT

Press, 2009.

ENNE, Ana Lucia. Juventude como espírito do tempo, faixa etária e estilo de vida: processos constitutivos de uma categoria-chave da modernidade. Comunicação Mídia e Consumo, v. 7, n. 20, p. 13-35, 2011.

GIDDENS, Anthony. Modernidade e identidade. Rio de Janeiro: Zahar, 2002.

HALL, Stuart. Identidade cultural na Pós-modernidade. Rio de Janeiro: DP\&A, 2000.

HARVEY, David. Condição pós-moderna. 14a ed. São Paulo: Loyola, 1992.

LEMOS, André; LÉVY, Pierre. O futuro da internet: em direção a uma ciberdemocracia planetária. São Paulo: Paulus, 2010.

LIPOVETSKY, Gilles. O império do efêmero: a moda e seu destino nas sociedades modernas. São Paulo: Companhia das Letras, 1989.

Companhia das Letras, 2015.

A estetização do mundo: viver na era do capitalismo artista. São Paulo:

MIYAZAWA, Pablo. 52 mitos da cultura pop: mentiras e verdades nos boatos do mundo do entretenimento. São Paulo: Paralela, 2016.

MORLEY, David. Medios, modernidad y tecnología: hacia una teoría interdisciplinaria de la cultura. Barcelona: Gedisa, 2007.

NOVAES, Henrique Tahan; DAGNINO, Renato. O fetiche da tecnologia. Revista ORG \& DEMO, v. 5, n. 2, p. 189-210, 2004.

PALFREY, John; GASSER, Urs. Nascidos na era digital: entendendo a primeira geração de nativos digitais. Porto Alegre, Artmed, 2011.

ROCHA, Everardo; PEREIRA, Cláudia. Juventude e consumo: um estudo sobre a comunicação na cultura contemporânea: Rio de Janeiro: Mauad X, 2009.

SANTAELLA, Lucia; LEMOS, Renata. Redes sociais digitais: a cognição conectiva do Twitter. São Paulo: Paulus, 2010.

TRAVANCAS, Isabel. Juventude e televisão: um estudo de recepção do Jornal Nacional entre jovens universitários cariocas. Rio de Janeiro: FGV, 2007.

TURKLE, Sherry. Alone together: why we expect more from technology and less from each other. New York: Basic Books, 2011.

VEJLGAARD, Henrik. Anatomy of a trend. Morrisville: Lulu Press, 2017. 